\title{
Assessment of Physics Lesson Planning and Teaching based on the 5Es Instruction Model in Rwanda Secondary Schools
}

\author{
Jeannette Nyirahagenimana ${ }^{1 *}$ (1), Jean Uwamahoro ${ }^{1}$ (i), Kizito Ndihokubwayo ${ }^{1}$ (])
}

\begin{abstract}
${ }^{1}$ African Center of Excellence for Innovative Teaching and Learning Mathematics and Science, College of Education, University of Rwanda, RWANDA *Corresponding Author: hagenijean@gmail.com
\end{abstract}

Citation: Nyirahagenimana, J., Uwamahoro, J., \& Ndihokubwayo, K. (2022). Assessment of Physics Lesson Planning and Teaching based on the 5Es Instruction Model in Rwanda Secondary Schools. Contemporary Mathematics and Science Education, 3(1), ep22004. https://doi.org/10.30935/conmaths/11573

\begin{abstract}
This research study focused on investigating the use of 5Es instructional model by physics teachers and how the model impacts the learning process of the basic concepts of electromagnetic waves in physics. In this study, six advanced-level physics teachers in four secondary schools within the Rwamagana district in Rwanda were purposively selected to participate. To collect data, 48 classroom observations were conducted, and data collected from classroom observation on the lesson delivery for all six teachers were analyzed through descriptive statistics. Before the training, the overall scores of observed lessons were low $(\mathrm{M}=2.07 ; \mathrm{SD}=0.68$ out of 5$)$ corresponding to $40.1 \%$ across all the 11 statements of classroom observation tool used to assess secondary schools STEM teachers' ability to plan and conduct teaching based on 5Es instructional model. After the training on 5Es instructional model, a significant improvement for all teachers in lesson preparation and its delivery was achieved. The high mean scores, $\mathrm{M}=4.79$ out of 5 scorerates (95\%) with low standard deviation, $\mathrm{SD}=0.40$ across all the 11 statements of similar classroom observation tool were obtained. The results after the training on the model indicated good performance for all teachers in terms of integrating exciting activities, discrepant events, relevant visualization guide, boosting learners' confidence to express their ideas in the teaching process, and using constructive scenarios that helped the learners to relate what they learned to real-life situations. Therefore, the use of the 5Es instructional model was found effective and recommended as a useful teaching approach for teachers.
\end{abstract}

Keywords: 5Es instructional model, active physics learning, electromagnetic waves, physics teacher, secondary school, Rwanda

Received: 2 Oct. 2021 Accepted: 13 Jan. 2022

\section{INTRODUCTION}

Physics is the bedrock of all science subjects due to its contributions in industries, engineering, medicine, telecommunication, transport (automobiles, trains, and flights) towards the quality of human life improvement (Ihejiamaizu et al., 2018). Effective physics teaching contributes to significantly sustaining the technology-based development of societies (Ceylan, 2008). Rwanda, as a landlocked country with limited natural resources, decided to build on competence-based and technology-based economy that will depend on capacity building through education in general and Science Technology Engineering and Mathematics (STEM), in particular. Encouraging innovations in the education sector is a central element of Rwandan ministry of education (MINEDUC) strategic focus (Tikly \& Milligan, 2017).

The worldwide survey (particularly among underdeveloped countries) indicates that physics is still not effectively taught, given that teachers struggle to teach basic concepts and mostly use inappropriate teaching approaches (Ramma et al., 2017). For instance, in Nigerian secondary schools, much emphasis is put on teaching to cover the scheme of work instead of teaching for everlasting learning (Ihejiamaizu et al., 2018). Due to this policy, 85\% of learners lose their interest and consider physics as a very difficult subject to learn (Olusola \& Rotimi, 2012). In the same case in Rwanda, the barrier or gap found in teaching and learning physics is linked to the teacher-centered approach used where teachers are knowledge transmitters instead of being facilitators of knowledge acquirement (Uwizeyimana et al., 2018). Therefore, an undesirable trend among other reasons is attributed to the ineffective pedagogical approach used since regardless of the training given by the Rwanda Basic Education Board (REB) and developmental partners (DPs), the teaching improvement of physics is not yet realized (Ndihokubwayo et al., 2020b).

Effective teaching science subjects, particularly physics, encounters many challenges such as inadequate teaching approach, insufficient science resources, and the large class size (Mekonnen, 2014). These challenges lead the learners to consider physics a difficult and abstract subject. Previous studies have shown students difficulties in learning physics concepts such as concepts of electromagnetic waves. Learners demonstrate difficulties understanding and interpreting diffraction, 
polarization, and interference effect (Ambrose et al., 1999). Similar challenges have also recently been investigated in learning optics and related phenomena, and these challenges have been mostly linked to instructional tools and teaching approaches used (Ndihokubwayo et al., 2020d).

Therefore, this study is in line with continuous efforts to improve STEM teaching, particularly physics, through research on innovative approaches that can make physics learning more active and meaningful to learners as far as their daily life experience is concerned. This is the reason why the present study builds on the constructivism theory. In constructivism, learners are effectively guided to take responsibility for their learning by developing skills, analyzing, evaluating evidence, discuss and talking to their peers about their understanding. Additionally, learners work collaboratively to solve problems and plan investigations (Sjøberg, 2010). This theory serves as the key for teachers to foster learner-centered methods and boost learners' problem-solving skills, critical thinking, innovation, and creativity (Dasdemir, 2016). In the present study, students are engaged in learning and given opportunity to explore the tools and materials in order to explain their outcome and then elaborate it to other daily life situation. The main goal of teaching physics is to make learners internalize and transfer their knowledge to make learning physics personal and apply knowledge learned in an actual situation (Andala \& Ng'umbi, 2016). To achieve this goal, a teacher must adopt and adapt effective teaching methods though many educators agree that learners learn more in an active learning environment than in a passive learning environment (James-Cook, 2016).

\section{The 5Es Instruction Model}

The 5E's instruction model (engage, explore, explain, elaborate, and evaluate) is a research-based teaching model that is both learnercentered and inquiry-based. In the engagement phase, learners are activated, and their prior knowledge is assessed. Its purpose is to capture learners' attention, interests and to determine their misconceptions (Duran \& Duran, 2004). In the exploration phase, the disequilibrium of the engagement is solved through learners' activities in their respective groups; their cognitive and physical abilities are developed. The teacher controls activities, provides adequate materials, and counters any misconceptions (Dasdemir, 2016). During the explain phase, learners present and explain their findings. The teacher is a shock absorber and directs learners' attention to key aspects of the prior phases and uses their explanations to explain scientific concepts (Ergin, 2012). For the elaboration phase, this is where learners' understanding is trained with new challenges or daily life situations (Duran \& Duran, 2004). Finally, in the evaluation phase, learners assess their learning and receive feedback on the adequate progress and ability, which helps the teacher make the appropriate decision (Guzel, 2017).

This learner-centered model is more about discovery and a deeper understanding of Physics (Sari et al., 2017). Through this model, learners are encouraged to develop their learning abilities by using activities carried out in the different teaching and learning cycles of 5Es. Teachers create a learning environment appropriate to the learners' understanding and avoid mass production (Andala \& Ng'umbi, 2016). It is believed that laying on a solid foundation in Physics education involves employing appropriate teaching and learning techniques (Ihejiamaizu et al., 2018)

The 5Es' model is derived from the concept that learners learn the most, retain knowledge, and have an opportunity to connect prior knowledge to new information with the acquisition of higher concept understanding (Mustafa, 2016). This 5Es learning and teaching model includes higher-order thinking skills (Muhammad et al., 2021). It advocates learner-centered learning and tries to provide a learning environment that would increase high-level learner motivation and thinking skills (Guzel, 2017). Models, animation, and simulation are among the aspects of the 5Es instructional model. The research found that integrating these aspects in teaching is very important and beneficial as they allow learners to talk about the subject and increase students' self-confidence (Dasdemir, 2016).

Previous research studies were conducted and demonstrated the effectiveness of using the 5Es instructional model in the high school classroom in both developed and developing countries and most of the results seem to come to the same conclusion. For instance, in research conducted in Turkey, 5Es models raised learners' academic achievement, and helped teachers identify and eliminate students misconceptions. The learners displayed positive attitudes towards the science course (Dasdemir, 2016). Other studies within the same country showed that the lessons studied through the 5Es model enhanced learners' positive attitudes by providing better understanding, increased the motivation related to the lesson, and created a positive effect on understanding abstract concepts (Guzel, 2017). In a study by Ihejiamaizu et al. (2018), it was found that teaching through 5Es instruction helped learners to improve their active participation in Physics. Similar studies conducted in Italy indicated that the 5Es instructional model helped the learners better understand the scientific concepts and getting interested in science and reasoning. However, the literature lacks studies that explore classroom environment after teachers have been trained on the lesson planning of 5Es instructional model.

The 5Es model was found to be appropriate for teachers in developing well-designed materials and instructional strategies in the science education field (Salihu \& Abubakar, 2020). Designed plans should challenge learners to use the given knowledge more effectively in the real world (Kara, 2018). Teaching and learning science through 5Es instructional model is a desirable teaching practice that has long been recommended due to its potential for helping learners to learn science with a deep understanding (Ward, 2016). The main purpose of this study was to evaluate physics teachers' ability in the use of the 5Es model in planning and lesson delivery with a focus on the teaching of basic electromagnetic waves physics concepts.

\section{RESEARCH METHODOLOGY}

\section{Research Design and Sample}

This study is based on classroom observation. Classroom observation is a well- known powerful practical approach to help teachers improve their teaching quality (Ndihokubwayo et al., 2020c). The quantitative research approach was used as the back born of this study to examine the process of intervention. Then, descriptive statistics were used to explicate the impact of a treatment (training on the use of 5Es instructional model) from six selected physics teachers that teach physics as a major subject in senior five class.

For this study, four schools located in Rwamagana District (Eastern Province of Rwanda) were visited, namely: College Marie Reine de la Paix, G.S. St Aloys Rwamagana, G.S. Apagie Musha, and Rwamagana Leaders School. The first two schools provided two teachers each while 
Table 1. The observation guiding tool used to assess the teaching based on the 5Es instructional model

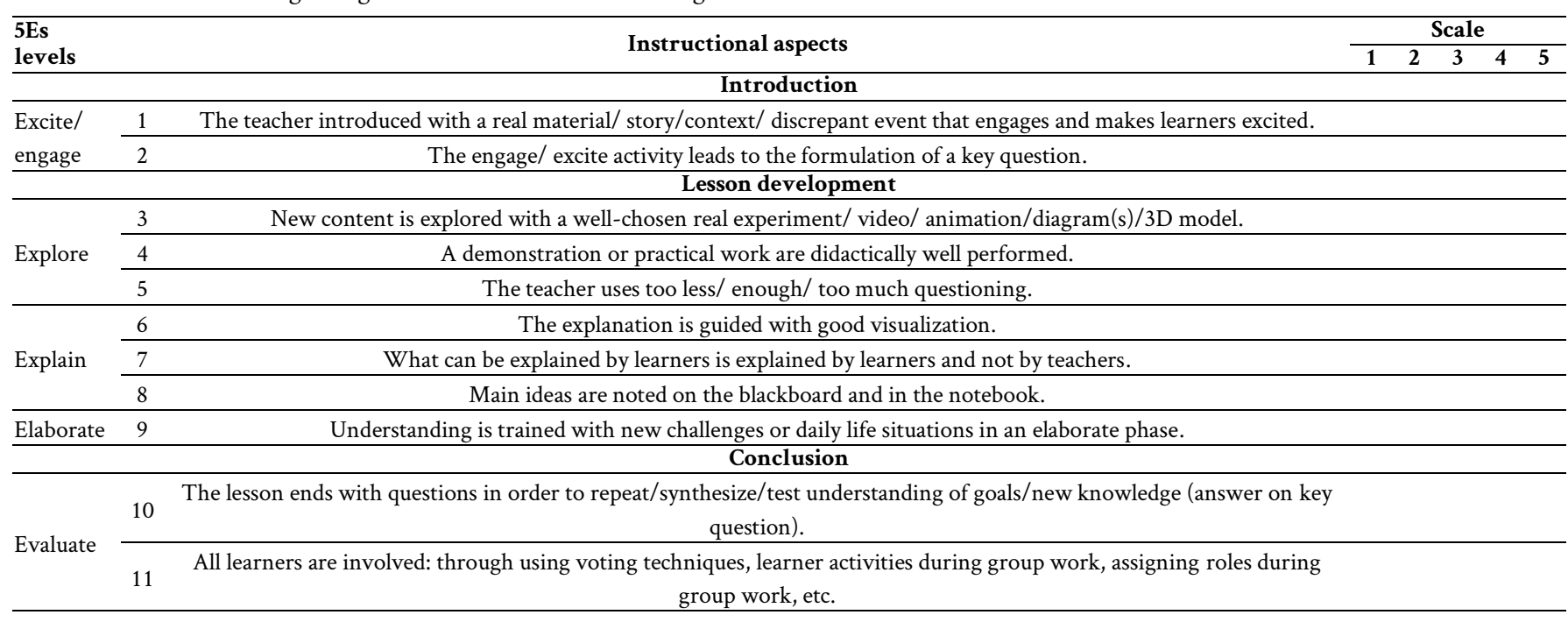

the last two schools provided one teacher each. Four schools were purposively selected based on the fact that these schools have a wide variety of combinations with physics as a major subject and that have well-equipped physics laboratories. Similarly, six teachers who teach advanced level (A level) physics in these four schools were all involved in the study. To collect data, ethical clearance was obtained from the unit of research and innovation at the University of Rwanda College of Education (URCE); then, headteachers and deputy headteachers were contacted to be informed on the study's purpose and objectives and seek permission to contact concerned teachers and learners.

Among teachers observed, two of them had already been trained under the Continous Professional Development (CPD) for STEM teachers. The Belgian Association for Development Cooperation and Technical Assistance (VVOB) program runs this program in collaboration with the College of Education of the University of Rwanda, intending to improve STEM teachers' skills towards effective implementation of the Competence-Based Curriculum (CBC).

\section{Training on 5Es Model and Data Collection}

The first author planned and organized the training for concerned teachers on 5Es instructional model for four days. The following activities were covered during the training; discussion, sharing ideas and presentation about 5Es instructional model, making lesson plans based on 5Es, and having teaching sessions for some physics lessons based on 5Es instructional model. Then, having a common understanding of regular class visits with the researcher based on their timetables after training. Teachers were observed four times for each with a classroom observation tool prepared by VVOB and URCE staff members to assess secondary school science teachers on their teaching practices before being trained on 5Es instructional model. In the same way, the researcher observed each teacher four times with an observation tool, and all data were recorded. The research was conducted with respect to ethical values, moral expectations, and rules governing the conduct of research, especially in data collection, such as anonymity and confidentiality of the data.

Forty-eight (48) classroom observations were conducted within a period of approximately 3months from January up to Mid-March 2021. It means eight classroom observations for each teacher before training and after training on the 5Es instructional model on related electromagnetic waves lessons. The tool guided all observations made in all classrooms to identify the applicability of the 5Es instructional model in teaching and learning physics in secondary schools (Table 1).

The tool (template) was developed for use in the CPD program for STEM teachers, which is run and complemented by VVOB in partnership with the University of Rwanda College of Education staff members (UR-CE, 2021).

\section{DATA ANALYSIS AND RESULTS}

To ensure the effectiveness and reliability of the research tool, before starting the intervention, the researchers (team of two) read the protocol several times for more understanding and comprehension. Then, the researchers observed a video delivering the physics lesson for reliability calculation. Usually, there are four cut-off points for reliability, which include excellent reliability ( 0.90 and above), high reliability (0.70-0.90), moderate reliability (0.50-0.70), and low reliability ( 0.50 and below) (Webb et al., 2006). After watching the first video, the observers found the 0.53 inter-observer reliability coefficients among the two pairs. Researchers watched a second video and found the 0.62 inter-observers' reliability, researchers watched the third video, and we found 0.72 , which is considered high-reliability coefficients. The inter-rater reliability was calculated using Pearson correlation product-moment where the rates agreement was computed and compared from two observers. APPENDIX A was used as a sample of a lesson plan based on 5Es. This was one among several lesson plans developed during training. Note that the study did not intend to analyze lesson plans, instead, we looked into usual teachers' lesson plans and planned together with them the lesson plans based on 5Es.

Six teachers were observed during their teaching. About 48 class observations were done in total. Eight observations were done for each teacher so that four observations were done before and after being trained on the 5Es instructional model. Data collected from the six (6) teachers were analyzed using descriptive statistics (mean and standard deviation) and presented in figures. Actually, the rating score of the observation tool used was 5 (from 1 to 5 ). This is to mean that among eleven items, each one is rated on five scales. Let say, if item 1 is not visualized being performed by learners or teachers, the observer scores it " 1 " score; if it is observed extensively and well-performed, then it is scored " 5 " out of 5 scores. Then, in analyzing each item, all four 


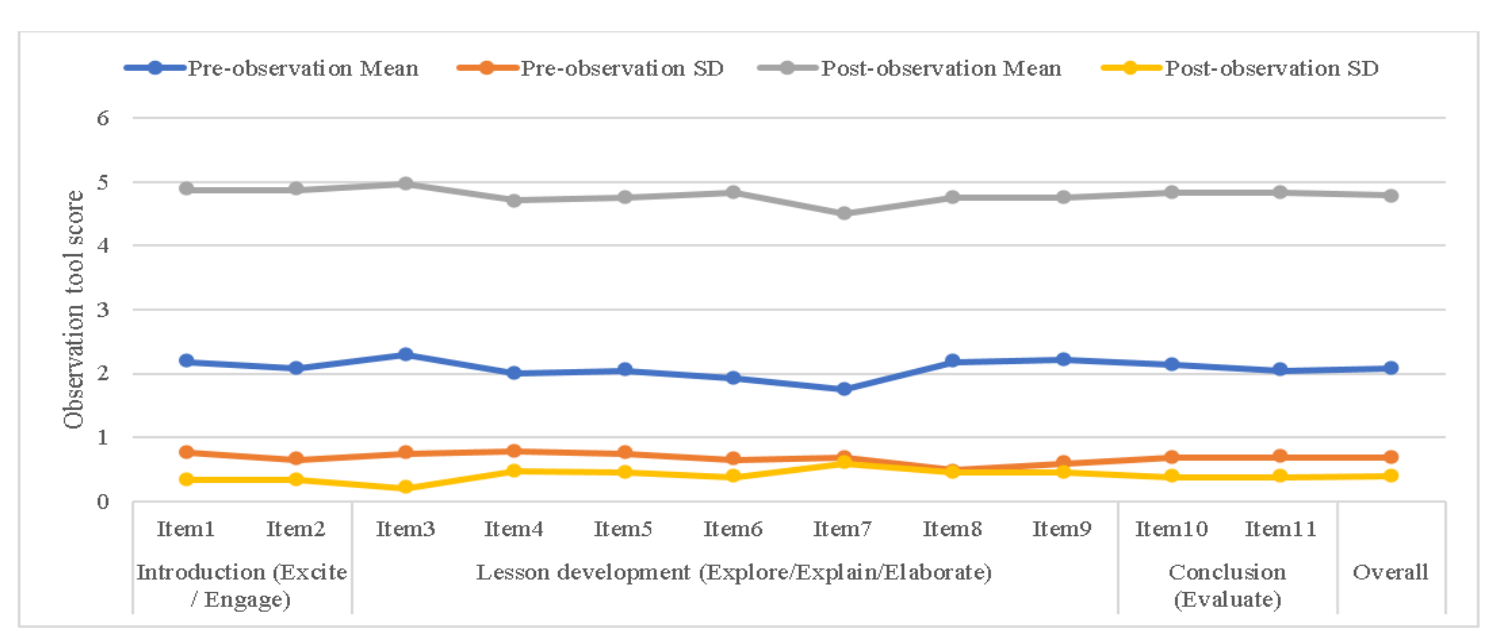

Figure 1. Classroom observation practices' score

observations made (either before or after training) were averaged and computed on 5 score since the maximum score is 5 . Then, the percent score also can be calculated; for instance, 4.79 out of 5 can be computed on $\%$ and become $95 \%$. Figure 1 indicates their respective average mean scores (M) and standard deviation (SD) calculated from scores of each statement for overall 48 observations.

From our results, the mean of each aspect was increased, and their standard deviation was shifted from the highest value to the lowest value, respectively, after the training. Briefly, the overall mean $(\mathrm{M}=2.07)$ and standard deviation $(\mathrm{SD}=0.68)$ before training shifted to $\mathrm{M}=4.79$ and $\mathrm{SD}=0.40$ after training. This highlights the improvement made due to training on the 5Es model delivered. The means on all the items of the observation tool used were also increased drastically, and their standard deviations have reduced (see Figure 1), showing how compact teachers consumed the new intervention of teaching with 5Es model instruction.

The lowest score of 1.75 out of 5 (35\%) was found at statement 7 (What can be explained by learners is explained by learners and not by teachers) before training. At this statement, the teacher was supposed to provide some guiding questions that will attract learners' curiosity in knowing the difference between electromagnetic waves and other types of waves based on their properties, as they were familiar with the properties of mechanical waves learned in previous lessons; for example, the teacher could formulate a question like; explain clearly the production and propagation of electromagnetic waves. And provide an opportunity for the learners to express their ideas. But it was not done; the teacher did not give the opportunity to learners who were there as guests. The teacher was a knowledge transmitter which justifies the lowest score obtained. The research showed that teacher-centered strategies had dominated most physics lessons (Qhobela \& Moru, 2014). In comparison, the highest score of 2.29 (45\%) was obtained at statements 3 (New content is explored with a well-chosen real experiment/video/animation/diagram(s)/3D model). On this statement, it would be better if the teacher prepared to guide questions and provided the related video and the diagram on the electromagnetic spectrum that could overcome the learners' misconceptions about the abstractness of electromagnetic waves.

After the training, the overall mean scores of 4.79 out of 5 (95\%) with a standard deviation of 0.40 were obtained across all the 11 statements for all six teachers. The lowest mean score of 4.5 (90\%) out of 5 was obtained at Statement-7. The mean was increased because the teachers gave the opportunity to learners to discuss some concepts and communicate their ideas. At this stage, the teachers were working together with the students as facilitators. It was found that Physics learners need the opportunity to think critically, collaborate with other students, participate in problem-solving activities and relate classroom knowledge with practical experiences outside the school setting (Appiah-Twumasi et al., 2021). For instance, in the case of the electromagnetic spectrum, the teacher created a scenario on the formation of the rainbow and asked them to discuss it in their respective groups and present their findings. This justifies the improvement made, though some students were absent-minded and shy. This is because to make a slight change in the teaching process of someone's habit requires a long-term process (Roland et al., 2016). The highest mean score was found on Statement-3 (New content is explored with a well-chosen real experiment/ video/ animation/diagram(s)/3D model with $M=4.96$ ) because all teachers have learned in undergraduate the impact of integrating ICT in education. Some of them have received training on both CBC organized by REB and ICT organized by Computer-Aided Design (CADI), even ICDL (International Computer Driving License) organized by AIMS. Even in the present training, the researcher provided enough practical activities that opened teachers' minds and were trained on how different education resources can be organized and be used appropriately in each of the 5Es phases.

For instance, the teacher provided a video to the learners about the difference between radio waves, microwaves, infrared, visible light, ultraviolet, and gamma rays and concluded that all differ due to the difference in frequency. It was generally observed that providing different resources to learners expand their thinking process and creates an interactive teaching and learning environment. For example, the impact of visualization activates cognitive activities that play crucial importance for learning specific physics topics like electromagnetic waves (Suyatna et al., 2017).

\section{FINDINGS AND DISCUSSION}

\section{Pre-Training Phase}

It was observed that the teachers did not put any effort in engaging phase; most of the teachers started with a presentation of the lesson without doing any activity related to the electromagnetic waves that can attract learners' attention at statements 1 and 2 means that the learners 
both prior knowledge and contributions were not considered. This strategy affects students' ability and clarifies the abstractness of electromagnetic waves once they do not get an opportunity to share their ideas, and leads to the class being bored. It would be great if the teacher started the lesson using a pride story about the formation of the rainbow once some learners were familiar with it and used learners' prior understanding instead of doing the whole presentation.

The existing instructions did not help students in deeper exploration at statements or items 4, 5, and 6 like to help them know some new vocabulary that can handle their understanding during their exploration. For example, it could be better if the teacher includes a video in his lesson plan on different types of the electromagnetic spectrum, as the learners have learned some concepts of light when it passes through a prism in optics in senior four means that some of them are familiar with visible light, ultraviolet and infra-red and ask them some questions about the difference between these three types and then expand it to the whole electromagnetic spectrum.

Teachers did not inspire coherent conceptual understanding of learners in explaining phase particular at statements 6, 7, and 8 (Main ideas are noted on the blackboard and in the notebook). Here teachers conducted the whole presentation on the arrangement of the electromagnetic spectrum and explained all basic concepts that governed electromagnetic spectrum, like the impact of frequency and wavelength on it without learners' interaction. The learners were there for the hearing, and the brilliant ones copied some explanations from their teachers, but the slower learners were there as the audience. It would be helpful if the teachers planed enough questions on the electromagnetic spectrum; for example, all objects emit electromagnetic radiation. The intensity and wavelength of the emitted radiation vary with the temperature of the object. Describe how the intensity of the emitted radiation changes with temperature, or gamma rays can cause cancer and treat cancer. Explain how gamma rays can do both. These can boost learners' presentation, and the teachers talk less.

In the elaboration phase at statement 9 (Understanding is trained with new challenges or daily life situations in elaborate phase), most of the teachers did not encourage learners to think out of the box; Normally good teacher must focus on learner's existing ideas seriously to change or challenge them for better understanding (Sjøberg, 2010). It was observed that teachers did not provide any challenging situations to help learners internalize what they learned in real-life situations. It would be constructive if the teachers used the video on the applications of the electromagnetic spectrum. This can open learners' minds as electromagnetic waves act in all domains or use challenging situations like; radiation from different regions of the electromagnetic spectrum can affect the human body in many ways. Discuss the different ways in which excessive exposure to electromagnetic radiations of various frequencies may cause damage to the human body.

In the evaluation phase, teachers did not care about the evaluation impact at statement $10 \& 11$, while the evaluation is considered the bridge in the teaching and learning process. In that phase, some teachers did not give an evaluation, and others provided it, which did not match with the learning objectives of the electromagnetic spectrum listed. It would be more productive if the teachers provided an evaluation that could give more details on what kind of positive transfer of learning gained by the individual learner for the ended lesson; for example, ask learners to make a summary on one page on the electromagnetic spectrum and make sure that all learning objectives are covered. The current research indicated that using information from the learning activities facilitates decision-making (Okoye et al., 2020). This practice motivates students and assures teachers to know the individual learner's progress. Practically teachers are concerned too much about time than the product of the lesson. A similar study was done in Rwanda, and Ndihokubwayo et al. (2020a) found that teachers plan for low levels of Bloom's cognitive and affective taxonomy domains and do not follow effective inquiry techniques along the stages of the lesson activities.

Generally, an overall pre-observation made, class started by providing materials to read for learners, then an oral presentation by teachers without students' contributions. This leads the students to approve that physics is a very difficult and abstract subject once their prior knowledge and ideas were not considered in their learning. We were curious why most teachers prefer to do everything during lesson delivery without considering students' interactions. The answer received from the teachers was that learner-centered is time-consuming while they have to cover the syllabus; therefore, the researchers concluded that the teacher-centered approach was still used.

\section{Training Phase}

During the training, we have discussed the existing teachers' lesson plans on the electromagnetic spectrum. Firstly we have asked them to highlight the encouraging information that can grab most learners attention that they have mentioned in their lesson plan, like some teaching materials that can help learner exploration, teachers activities accompanied by related key questions on electromagnetic spectrum lessons, hands-on activities for learners that can help them to participate in their learning process, the challenging situation that can help them to construct their knowledge as well as evaluation related to the learning target of the lesson. It was found that most of the lesson plan analyzed lacked some of the above aspects and were not helpful for learners nowadays. Then we discussed what can be a focused on in order to pull or attract learners' attention in the lesson, what kind of creativity and innovation that teacher should include in the lesson plan that can lead to the involvement of all learners.

A hot discussion took place among teachers, and they came up with interesting information like, they can introduce the lesson by using pride stories about the electromagnetic spectrum, by using familiar examples like a rainbow as well as exciting activities with key questions. Reaching the exploration part some teachers said that they did not have tangible material for learners to manipulate apart from learners physics textbooks on the electromagnetic spectrum, at this point we shared the impact of using ICT in their teaching process, the outcomes from their discussion were diagrams of electromagnetic spectrum, videos, animation, simulation as well as models can be obtained from our computer which coincided with the expected ones, and the teacher must provide enough questions for deeper research. What will be the teachers and learners' activities on the electromagnetic spectrum in the explanation part; they provided the following points, the teacher must provide enough high order thinking questions, and clarified some concepts which were not well explained during learners' presentation, and adding some scientific information that did not appear in learners' presentation. In that part, learners get an opportunity to express their ideas and note them on the blackboard to support visual learning. For better extension, they said that; more challenging situations would be used in order to open learners' minds, like how the electromagnetic spectrum was used to check if the banknote is genuine. 
Finally, we have discussed the impact of evaluation in the teaching and learning process and different strategies of evaluating, like voting cards, 1-2-3, exit tickets, and so on. Then we concluded that any instructional model that contains the above-mentioned aspects is what we call 5Es (engage, explore, explain, elaborate, evaluate) instructional model. In all training processes, some concept notes from continuous professional development textbooks published by VVOB and URCE staff members as well as the lesson delivery protocol on 5Es aspects were used.

\section{Post-Training Phase}

\section{Excite or engage phase}

The intervention of 5Es boosted teachers' creativity and innovation, as confirmed by the mean scores of item- 1 and 2 recorded in the engaging phase. The teacher was found engaging the learners with exciting activities like rainbow formation and a discrepant event of taking a beaker full of water and torch on that beaker using the light of their phones. Some colors were displayed on the wall of the class, and ask some key questions about that, which in turn all students' attention was attracted and involved.

\section{Exploration phase}

A learning concentration of learners was observed clearly in the exploration phase, where learners' curiosity exceeds the expectation. Students were very interested in looking through a spectroscope and writing their observations in their notebooks. They were thirsty to read some constructive information like the impact of frequency or wavelength in the arrangement of observed colors as well as asking the meaning of some new words like the difference between spectrum and spectra for better understanding. During the reading activity, the reading culture was obviously seen. Reaching to the video, learners watched it quietly and attentively so that their listening skills were developed. According to Dasdemir (2016), video and animation actualized learners by engaging them actively in the lesson through the facility of illusion abstract phenomena, increasing their self-confidence, and providing opportunities for them to talk about the subject. The teachers allowed the learners to discuss in their respective groups the individual findings and use the common flipchart for each to write the answers on the guiding or key questions on the electromagnetic spectrum posted by their teachers before starting the exploration phase.

\section{Explaining phase}

Active participation was observed in the explaining phase shown in item 3-9. Each group of learners posted their findings on the chalkboard; the representative of each group presented the findings on behalf of the group; a lot of questions from other groups were asked to the presenting one; for instance, why the colors of the electromagnetic spectrum are not mixed. It was very impressive to see how learners explained clearly the fact behind that arrangement of colors with the aid of flipchart and said that it is due to the difference in frequency or difference in wavelength and difference in energy, additionally said that from radio waves to gamma rays' frequency and energy increase but wavelength decreases. Apart from enough questions provided by the teachers in that phase, they also provided a better clarification and harmonization on learners' ideas on some concepts of learners' presentation with the aid of diagrams of the electromagnetic spectrum where both visual learning and critical analysis of learners were improved. The same observation was made in learning the magnetic hysteresis loop through the 5Es instructional model, where students understand their own hands-on activities due to self-involvement (Shah et al., 2019).

\section{Elaborate phase}

Reaching the elaboration phase, which is so-called the understanding show, the teachers provided some challenging situations on the applications of the electromagnetic spectrum. An example was to write a page on the positive impact of the electromagnetic spectrum on real-life situations. The learners' answers showed that it could be applied in telecommunication, medicine, industries, transport, etc., which were $100 \%$ correct. Learners watched the video on applications of the electromagnetic spectrum for further inputs. This is in the same line as the observation that students achieved more when taught using PhET simulations and YouTube videos (Ndihokubwayo et al., 2020b).

\section{Evaluation phase}

In the evaluation phase, all teachers got the impact of evaluation in the teaching and learning process, as confirmed by item 10 and 11 . The researchers were excited about the upcoming poem composed by learners on the electromagnetic spectrum and its real applications. Therefore, obtaining frequent feedback on teaching; getting regular insight on student learning plays a central role in decision making (Clipa, 2015).

In constructivism, the learner actively constructs knowledge, and that construction of knowledge is linked to their interaction with the physical world (Sjøberg, 2010). The outcomes of our study across all the 11 statements for all six teachers indicated teaching and learning physics through the 5Es model rooted in constructivism theory lead to the creation of constructivist classroom. This will highly boost the implementation of a competence-based curriculum due to its potential in its different phases and therefore overcome completely teachercentered teaching approaches.

\section{CONCLUSIONS AND LIMITATIONS OF THE STUDY}

This study measured changes made while implementing the 5Es model in the Rwandan classrooms. Firstly, six teachers from four schools in the Rwamagana district were observed in their routine practices. Secondly, training intervention on the use of 5Es instruction was delivered to these teachers by planning a lesson together and discussing how each component of the model is implemented. Lastly, we observed the same teachers after training. The study was basically analyzed in a quantitative approach. However, results were described qualitatively. Major findings from this study indicate that physics teachers' ability in the use of the 5Es instructional model in schools is still low, and this impacts negatively the student's engagement in all expected activities for a full lesson on electromagnetic waves. However, obtained results through mean and standard deviations, after training, demonstrate significant improvement of physics teachers' ability to effectively apply the 5 Es instruction both in planning and delivering the lesson.

Based on this study outcome and strong empirical support stated in this study, the authors believe that the 5Es instructional model is a very practicable instructional strategy that makes teaching and learning Physics more concrete. However, we did not analyze existing lesson plans (before training on 5Es) and prepared lesson plans based on 5Es 
(after training); therefore, our future research will focus on this. We analyzed descriptive statistics. Therefore, more robust research is needed to employ a large sample size of teachers and has room to analyze the data with inferential statistics. It can be recommended that similar studies be conducted in different schools with a larger sample size to increase the generalizability of the study. Particularly, outcomes from this study indicate the importance of the 5Es model while introducing to learners some more abstract physics concepts such as electromagnetic waves.

Author contributions: All authors were involved in concept, design, collection of data, interpretation, writing, and critically revising the article. All authors approve final version of the article.

Funding: The authors received financial support for the research and/or authorship of this article from African Center of Excellence for Innovative Teaching and Learning Mathematics and Science (ACEITLMS).

Acknowledgements: The authors would like to pay thankful recognitions to VVOB and URCE lecturers for developing the observation tool used. The authors appreciated schools, teachers, and students who voluntarily participated in this study. Reviewers who reviewed and editors who processed this manuscript are well appreciated.

Declaration of interest: Authors declare no competing interest.

Data availability: Data generated or analysed during this study are available from the authors on request.

\section{REFERENCES}

Ambrose, B. S., Heron, P. R. L., Vokos, S., \& McDermott, L. C. (1999). Student understanding of light as an electromagnetic wave: Relating the formalism to physical phenomena. American Journal of Physics, 67(10), 891-898. https://doi.org/10.1119/1.19144

Andala, O. H., \& Ng'umbi, M. (2016). The teaching methods used in universities in Rwanda and their effect on the students' academic performance. Educational Management and Curriculum Studies, 3(5), 1-18.

Appiah-Twumasi, E., Nti, D., Acheampong, R., \& Eminah, C. (2021). Effect of the $5 \mathrm{E}$ instructional model on physics academic achievement based on gender and students' ability: A case of Berekum senior high schools in Ghana. East African Journal of Education and Social Sciences, 2(1), 1-10. https://doi.org/10.46606/ eajess2021v02i01.0060

Ceylan, E. (2008). Effects of 5E learning cycle model on understanding of state of matter and solubility concepts. Middle East Technical University. https://open.metu.edu.tr/handle/11511/17960

Clipa, O. (2015). Roles and strategies of teacher evaluation: Teachers' perceptions. Procedia-Social and Behavioral Sciences, 180, 916-923. https://doi.org/10.1016/j.sbspro.2015.02.243

Dasdemir, I. (2016). The effect of the 5E instructional model enriched with cooperative learning and animations on seventh-grade students' academic achievement and scientific attitudes. International Electronic Journal of Elementary Education, 9(1), 21-38.

Duran, L., \& Duran, E. (2004). The 5E instructional model: A learning cycle approach for inquiry-based science teaching. Science Education Review, 3(2), 49-58.

Ergin, I. (2012). Constructivist approach based 5E model and usability instructional physics. Edvcatio Physicorvm Qvo Non Ascendam, 6(1), 14-20.
Guzel, H. (2017). The effect of electric current teaching based upon the $5 \mathrm{E}$ model on academic achievement and attitudes of students. AsiaPacific Forum on Science Learning and Teaching, 18(2), 1-21. https:// www.eduhk.hk/apfslt/download/v18_issue2_files/guzel.pdf

Ihejiamaizu, C. C., Ukor, D. D., \& Neji, H. A. (2018). Utilization of 5Es constructivist approach for enhancing the teaching of difficult concepts in biology. Global Journal of Educational Research, 17(1), 55. https://doi.org/10.4314/gjedr.v17i1.8

James-Cook. (2016). Promoting active teaching and learning: A guide for staff. James Cook University, Australia. https://www.jcu.edu.au/ __data/assets/pdf_file/0006/227868/Promoting-ActiveTeaching-and-Learning.pdf

Kara, M. (2018). A systematic literature review: Constructivism in multidisciplinary learning environments. International Journal of Academic Research in Education, 19-26. https://doi.org/10.17985/ ijare.520666

Mekonnen, S. (2014). Problems challenging the academic performance of physics students in higher governmental institutions in the case of Arbaminch, Wolayita Sodo, Hawassa and Dilla Universities. Natural Science, 06(05), 362-375. https://doi.org/10.4236/ns.2014. 65037

Muhammad, B. A., Omwirhirem, E. M., \& Abubakar, S. (2021). Effects of 5Es teaching cycle on retention ability among secondary school students of varied ability in mole concept, in Zaria Education Zone, Kaduna State. ATBU Journal of Science, Technology and Education, 9(2), 106-113.

Mustafa, M. E. I. (2016). The impact of experiencing 5E learning cycle on developing science teachers' technological pedagogical content knowledge (TPACK). Universal Journal of Educational Research, 4(10), 2244-2267. https://doi.org/10.13189/ujer.2016.041003

Ndihokubwayo, K., Ndayambaje, I., \& Uwamahoro, J. (2020a). Analysis of lesson plans from Rwandan physics teachers. International Journal of Learning, Teaching and Educational Research, 19(12), 1-29. https://doi.org/10.26803/ijlter.19.12.1

Ndihokubwayo, K., Uwamahoro, J., \& Ndayambaje, I. (2020b). Effectiveness of PhET simulations and YouTube videos to improve the learning of optics in Rwandan secondary schools. African Journal of Research in Mathematics, Science and Technology Education, 24(2), 253-265. https://doi.org/10.1080/18117295.2020.1818042

Ndihokubwayo, K., Uwamahoro, J., \& Ndayambaje, I. (2020c). Implementation of the competence-based learning in Rwandan physics classrooms: First assessment based on the reformed teaching observation protocol. EURASIA Journal of Mathematics, Science and Technology Education, 16(9), 1-8. https://doi.org/10. 29333/ejmste/8395

Ndihokubwayo, K., Uwamahoro, J., Ndayambaje, I., \& Ralph, M. (2020d). Light phenomena conceptual assessment: An inventory tool for teachers. Physics Education, 55(3), 035009. https://doi.org/ 10.1088/1361-6552/ab6f20

Okoye, K., Arrona-Palacios, A., Camacho-Zuñiga, C., Hammout, N., Nakamura, E. L., Escamilla, J., \& Hosseini, S. (2020). Impact of students evaluation of teaching: A text analysis of the teachers qualities by gender. International Journal of Educational Technology in Higher Education, 17(1), 1-27. https://doi.org/10.1186/s41239-02000224-z 
Olusola, O. O., \& Rotimi, C. O. (2012). Attitudes of students towards the study of physics in College of Education Ikere. American International Journal of Contemporary Research, 2(12), 86-89.

Qhobela, M., \& Moru, E. K. (2014). Understanding challenges physics teachers come across as they implement learner-centred approaches in Lesotho. African Journal of Research in Mathematics, Science and Technology Education, 18(1), 63-74. https://doi.org/10.1080/ 10288457.2014.884351

Ramma, Y., Bholoa, A., Watts, M., \& Nadal, P. S. (2017). Teaching and learning physics using technology: Making a case for the affective domain. Education Inquiry, 9(2), 210-236. https://doi.org/10.1080/ 20004508.2017.1343606

Roland, N., Frenay, M., \& Boudrenghien, G. (2016). Towards a better understanding of academic persistence among fresh-men: A qualitative approach. Journal of Education and Training Studies, 4(12), 175-188. https://doi.org/10.11114/jets.v4i12.1904

Salihu, J. J., \& Abubakar, I. (2020). Effects of educational field trips on social studies students' academic achievement in junior secondary schools in Kaduna State, Nigeria. Education, Sustainability and Society, 3(2), 41-44. https://doi.org/10.26480/ess.02.2020.41.44

Sari, U., Hajiomer, A., Guven, K., \& Faruk, O. (2017). Effects of the 5E teaching model using interactive simulation on achievement and attitude in physics education. International Journal of Innovation in Science and Mathematics Education, 25(3), 20-35.

Shah, K., Muhammad, Y., Khalid, S., \& Uzma, N. (2019). Using 5e's instructional model to study the concept of magnetic hysteresis curve in physics. Language in India, 19(10), 48-62.
Sjøberg, S. (2010). Constructivism and learning. International Encyclopedia of Education, 485-490. https://doi.org/10.1016/B9780-08-044894-7.00467-X

Suyatna, A., Anggraini, D., Agustina, D., \& Widyastuti, D. (2017). The role of visual representation in physics learning: Dynamic versus static visualization. Journal of Physics: Conference Series, 909(1), 012048. https://doi.org/10.1088/1742-6596/909/1/012048

Tikly, L., \& Milligan, L. (2017). Learning from innovation for education in Rwanda. In Ebook (pp. 1-41). University of Bristol.

UR-CE. (2021). Continous professional development certificate in educational mentoring and coaching for STEM teachers, student manual, module 2: Technological pedagogical content knowledge and gender in STEM education (PDM1142), Fourth edition. vvob.org. https://rwanda.vvob.org/sites/rwanda/files/ cpd_certificate_educational_mentorship_and_coaching_for_stem module_2_-_4th_edition_v0.00_20210415_small_version.pdf

Uwizeyimana, D., Yadav, L. L., Musengimana, T., \& Uwamahoro, J. (2018). The impact of teaching approaches on effective physics learning: An investigation conducted in five secondary schools in Rusizi District, Rwanda. Rwandan Journal of Education, 4(2), 4-14.

Ward, P. (2016). How select groups of preservice science teachers with inquiry orientations view teaching and learning science through inquiry. University of Arkansas, Fayetteville. https://scholarworks. uark.edu/cgi/viewcontent.cgi? referer $=\&$ httpsredir $=1 \&$ article $=337$ $5 \&$ context=etd

Webb, N. M., Shavelson, R. J., \& Haertel, E. H. (2006). 4 reliability coefficients and generalizability theory. Handbook of Statistics, 26, 81124. https://doi.org/10.1016/S0169-7161(06)26004-8 


\section{APPENDIX A-LESSON PLAN ON ELECTROMAGNETIC WAVE SPECTRUM}

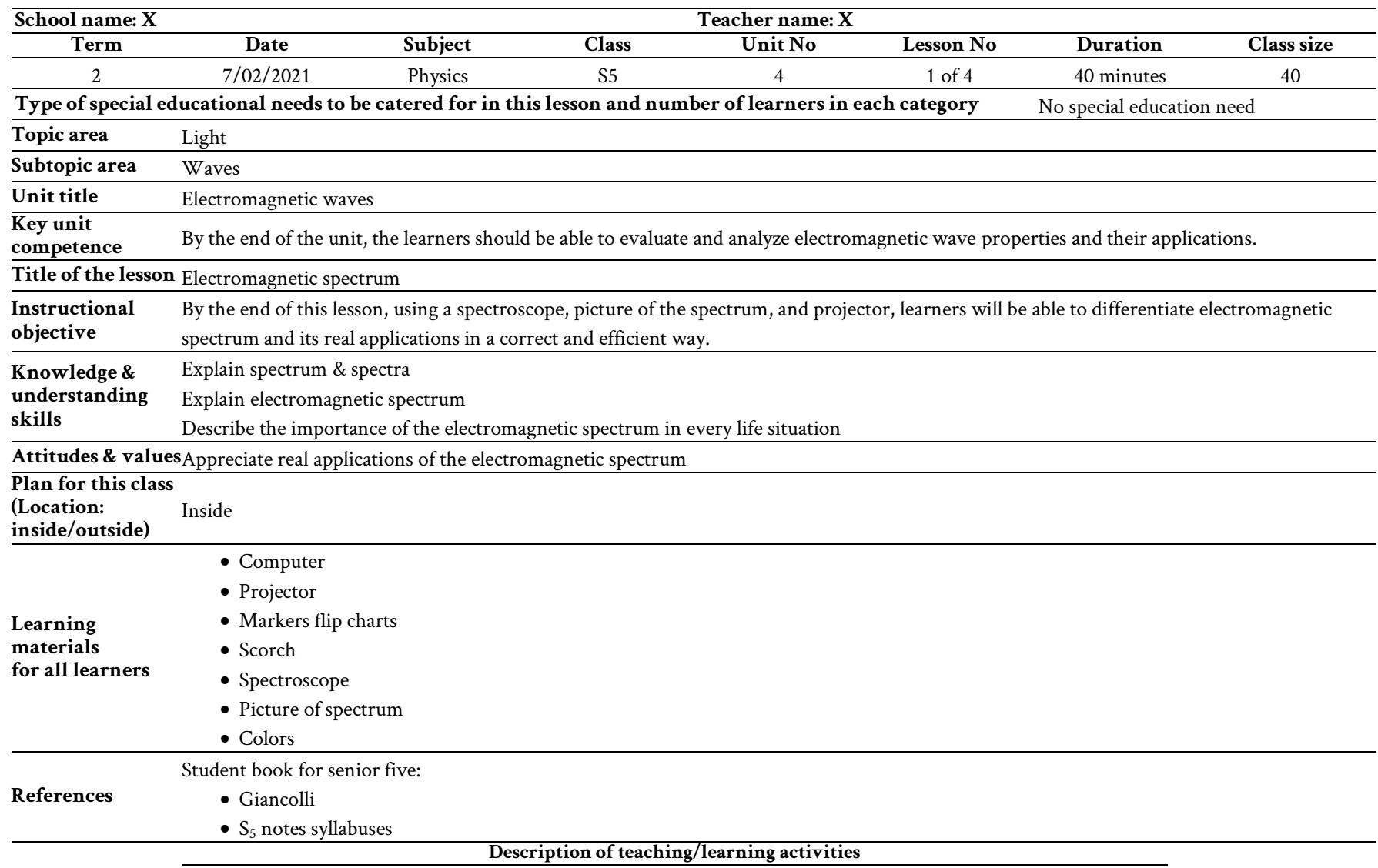

The lesson will involve mainly activities performed by learners either individually or in groups. In engage, the teacher will Generic competences perform some activities, and learners will answer probing questions related to the activities. In explore phase, they will explore the key question through watching a video and answering the asked questions. They will also carry out a reading of a text and

Timing for each step Electromagnetic wave spectrum. In explain phase, students will present their findings. Next, the teacher will complete students' ideas, and learners will take notes and ask questions for clarification and deeper understanding. In the elaboration phase, learners will work on challenging questions and post their answers for sharing with the rest of the class. Finally, the lesson will be ended by an evaluation by carrying out a short quiz and being given homework for further study. Teacher's activities

Excite/engage ( 7 minutes)

Guess who I am: I am a multi-colored circular arc, and I get my origin due to reflection, refraction, and dispersion phenomena when sunlight interacts with water droplets; I always appear in the section of the sky directly opposed to Introduction (7 min) the sun.

The teacher performed an experiment by using the beaker containing water and the source of light. He sent light through that beaker, and different colors were formed on the screen.

Key question:

What do you think about the stratified formed colors?

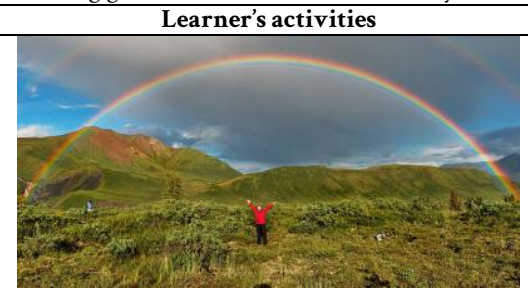

Students work in pairs, read and discuss the scenario provided and come up with the answer related to the scenario: rainbow.

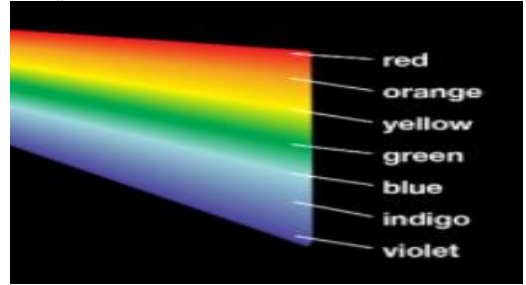

Students conduct the discussion in pairs, and answer the asked questions and write their brainstormed answers on the blackboard.
Communication skills are developed through questioning and answering orally in respecting learners' ideas.

Gender education is emphasized by encouraging all learners' regardless of sex, to participate in the learning and teaching process. 
APPENDIX A-LESSON PLAN ON ELECTROMAGNETIC WAVE SPECTRUM (CONTINUED)

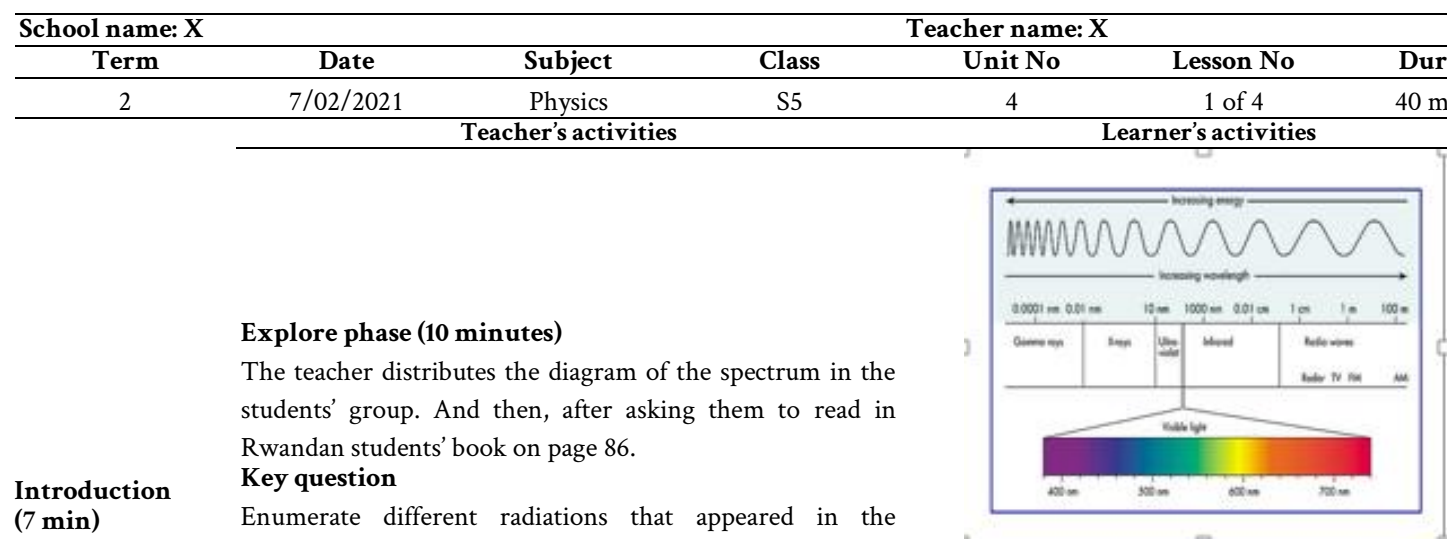
electromagnetic spectrum, and how are they different? Reading the questions before watching the video. The teacher provides videos to enhance learners' The following are expected answers from learners: understanding. The teacher moves around to check what they are doing and

- A spectrum is dark when it is absorbed by a support slow learners. material, while a spectrum is bright when it is emitted.

Communication skills are developed through questioning and answering orally in respecting learners' ideas.

Gender education is emphasized by encouraging all learners' regardless of sex, to participate in the learning and teaching process.

- Spectra differ due to their difference in wavelength and in their frequency.

The real applications of the spectrum are applied in engineers' machine.

\section{Explain (10 minutes)}

The teacher randomly chooses one boy and one girl to make a presentation on the blackboard

The teacher harmonizes their ideas and facilities in explaining some electromagnetic spectrum concepts. The teacher stimulates the learners to ask questions as well as provide answers to their colleagues' questions. The teacher completes students' answers and provides a scientific explanation of concepts related to the electromagnetic spectrum. Elaborate (6 minutes)

The teacher shows a video about the application of electromagnetic spectrum and displayed this picture to them, and ask them to write a summary on the applications of the electromagnetic spectrum.

Evaluate ( 7 minutes)

Development (26 Short quiz: This diagram shows the different regions of the min) electromagnetic (EM) spectrum.

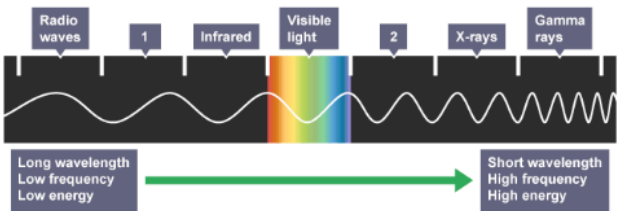

a. Identify regions 1 and 2 from the diagram above[ 2 marks].

b. Choose the correct phrase in each bracket below [ 3 marks]:

1. Visible light travels [faster than/at the same speed as / slower than] radio waves.

2. The frequency of visible light is [higher than/the same as/lower than] the frequency of X-rays.

The selected ones present their ideas: Fellow students will listen to the presentations and note down the keynotes.

Go in groups and follow instructions.

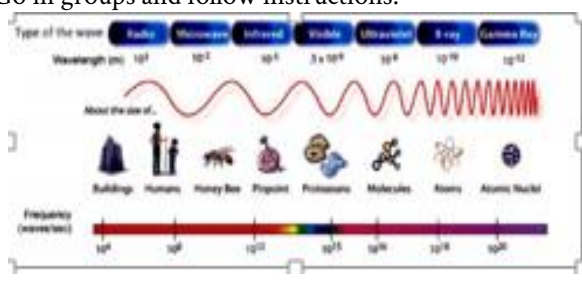

Write answers for the short quiz on the sheet of the paper:

Expected answers:

a-1. Microwave

a-2. Ultraviolet rays

b-1. At the same speed

b-2. Lower than

b-3. Shorter than

Communication and critical thinking

skills: Group

discussions and

reflecting on teacher's questions.

Critical thinking and research skills as they are asked to come up with specific notes or answers from a large body of information from the video and a text.

Inclusive education as all learners are encouraged to participate actively without any kind of

discrimination.

Cooperation \&

communication skills as they make presentations and ask questions.

Gender education as both girls and boys are given equal opportunity

to present their findings.

3. The wavelength of visible light is [longer than/the same as/shorter than] the wavelength of radio waves 